Rurali: Revista interdisciplinar de estudios rurales, N. 2, V.1, julio a diciembre de 2021, pp. 3653

https://doi.org/10.7203/Rurali.1.2.2041

\title{
Experiencias de presupuestos participativos en España ante la Covid-
} 19.

\author{
Experiences of participatory budgets in Spain infornt Covid-19.
}

\author{
Álvaro Romero Algora
}

Resumen.

Los presupuestos participativos son en la actualidad uno de los instrumentos más relevantes de la democracia participativa a nivel mundial. La crisis sanitaria producida por la Covid-19 durante 2020 ha generado una situación de excepcionalidad en todos los niveles del Estado, y los presupuestos participativos no han sido una excepción. Varios municipios españoles se han visto obligados a diseñar nuevas metodologías para dar cabida a las propuestas de los vecinos. Mientras que otros, debido a la difícil situación o por la poca voluntad política, han paralizado su asignación participativa.

\begin{abstract}
Participatory budgets are currently one of the most relevant instruments of participatory democracy. The health crisis caused by Covid-19 during 2020 has generated an exceptional situation at all levels of the State, and participatory budgets have not been an exception. Several Spanish municipalities have been forced to design new methodologies to accommodate the proposals of the neighbors. While others, due to the difficult situation or lack of political will, have paralyzed their participatory allocation.
\end{abstract}

Palabras Clave: presupuestos participativos, mecanismos de participación, Covid-19, pandemia, municipalismo.

Keywords: participatory budgets, mechanisms of participation, Covid-19, pandemic, municipalism. 
Rurali: Revista interdisciplinar de estudios rurales, N. 2, V.1, julio a diciembre de 2021, pp. 36-

\section{Introducción}

El objetivo de este texto es analizar y exponer el modo en el que distintos municipios españoles han gestionado sus experiencias de participación presupuestaria ante al desafío que ha supuesto la crisis sanitaria causada por la Covid-19 en 2020. En los últimos años el presupuesto participativo ha supuesto una de las herramientas más reivindicadas por distintos grupos políticos para revitalizar la política municipal en España, aunque no una nueva, pues lleva practicándose en nuestro país desde 2001. Sin embargo, fue después de las elecciones municipales de 2015 cuando los españoles presenciamos una revitalización de las propuestas municipalistas en prácticamente todo el territorio nacional (Monterde, 2019). En lo que respecta a los presupuestos participativos, esto ha supuesto la recuperación de experiencias paralizadas como la de Sevilla (Alonso, 2017) y la implantación de otras nuevas como en Valencia (Barandela, 2017). Ya sean en grandes ciudades o pequeñas localidades, no cabe duda de que las experiencias participativas se han multiplicado en los últimos años.

Pese a su éxito, los presupuestos participativos han padecido numerosos obstáculos en su elaboración y en su continuidad a lo largo de los años (Grompone, 2006; Pineda, 2009; Ramírez, 2009; Fernández y Pineda, 2010). Se tratan de prácticas que, al no existir una metodología única, debemos concebirlas como procesos sujetos a las realidades particulares en las que se desenvuelven, como la coyuntura económica y política, así como el nivel de compromiso de sus participantes. La crisis sanitaria producida por la Covid-19 durante 2020 se suma a estas dificultades. Muchos municipios se vieron afectados por la nueva situación de excepcionalidad, obligando a unos a diseñar nuevas metodologías para dar cabida a las propuestas vecinales, mientras que otros limitaron o incluso paralizaron la asignación participativa en el presupuesto.

El presente texto muestra ejemplos de distintos municipios españoles, ya sean grandes, medianos o pequeños, urbanos o rurales. La muestra es pequeña pero representativa del tipo de experiencias vividas durante estos meses en España. Los criterios para que un municipio sea considerado "grande", "mediano" o "pequeño" son algo arbitrarios, variando entre comunidades autónomas, lo que ha llevado a algunos autores a señalar los límites que presenta la legislación actual en lo concerniente al complejo y variado mapa municipal español (Burgueño y Guerrero, 2014; Albet, 2019). Con el fin de establecer un criterio objetivo para este trabajo, seguiremos los límites demográficos escalonados definidos en el artículo 26 de la Ley 7/1985 Reguladora de las Bases del Régimen Local, según umbrales de 5.000, 20.000 y 50.000 habitantes. También la Ley 57/2003, de medidas para la modernización del gobierno local, la cual establece como grandes ciudades a aquellos municipios con más de 250.000 habitantes; así como la Ley 45/2007, para el desarrollo sostenible del medio rural, la cual en su artículo 3 define el medio rural como "el espacio geográfico formado por la agregación de municipios o entidades locales menores definidos por las administraciones competentes que posean una población inferior a 30.000 habitantes y una densidad inferior a 100 habitantes por km2 ". Así 
Rurali: Revista interdisciplinar de estudios rurales, N. 2, V.1, julio a diciembre de 2021, pp. 3653

mismo, son considerados como municipios rurales de pequeño tamaño aquellos que posean una población inferior a los 5.000 habitantes y que estén integrados en el medio rural.

Este texto está dividido en cuatro apartados. Primero, se presentará el origen y corriente de pensamiento en el que se enmarca el presupuesto participativo. En segundo lugar, su implantación y desarrollo en España. En el tercer apartado, se expondrán una serie de experiencias participativas presupuestarias y cómo la crisis sanitaria ha influido en ellas. La información será extraída principalmente de los comunicados oficiales de los ayuntamientos y de distintos medios de comunicación. Por último, acabaremos con una breve reflexión a modo de conclusión.

\section{Origen de los presupuestos participativos}

Durante la segunda mitad del siglo XX surgieron en el seno de los países capitalistas desarrollados una serie de transformaciones socioeconómicas, las cuales provocarían profundos cambios en la manera en la que hasta entonces se había concebido la democracia. Numerosos pensadores y colectivos sometieron a crítica la concepción elitista y competitiva de la democracia defendida por autores como J. A. Schumpeter (1984), apostando por revivir viejas interpretaciones que alababan las virtudes educativas de la participación política. Macpherson (2003) señalaba que el nacimiento de la democracia participativa surgió con fuerza junto con los movimientos estudiantiles de la denominada Nueva Izquierda en la década de los sesenta, especialmente durante el famoso mayo del 68, quienes exigían una mayor participación en la toma de decisiones de la administración universitaria. De esta manera, empezó a circular la idea de que los espacios en los que los ciudadanos tomaran decisiones políticas colectivas debían extenderse. La comunidad no sería vista como una potencial amenaza a la libertad, sino que es precisamente a través de esta donde alcanza su verdadero sentido y alcance (Pérez, 2014).

La pérdida de confianza en los gobernantes elegidos, la desigual distribución de riqueza y poder entre clases sociales o la falta de comunicación entre la ciudadanía y una burocracia estatal cada vez más compleja son sólo algunas de las críticas realizadas a las democracias liberales tradicionales. Las propuestas participacionistas para superar dichos déficits han sido muy amplias, por ejemplo, y para el tema que nos atañe, el derecho a una ciudad más participativa, cuyas raíces intelectuales podemos rastrear en la influyente obra de Henri Lefebvre Le Droit a la Ville (1967), donde se reivindica la ciudad como espacio privilegiado en la lucha contra el capitalismo. Como se ve, las reivindicaciones municipalistas vienen de lejos. Sin embargo, no sería hasta la década de los ochenta y noventa cuando conceptos como "participación" o "deliberación" se asientan dentro del debate académico primero, y del público después.

A diferencia de sus concepciones iniciales, la mayoría de las iniciativas municipalistas que se han acabado implantando a lo largo de los años no pretenden ni cambiar la 
Rurali: Revista interdisciplinar de estudios rurales, N. 2, V.1, julio a diciembre de 2021, pp. 3653

Constitución ni el sistema representativo, de hecho, parten de sus principios liberales democráticos para otorgar a los vecinos la posibilidad de decidir sobre asuntos de interés público o vecinal. Para ello, la descentralización sería la fórmula escogida para fomentar la participación local, siendo el ayuntamiento el espacio propicio para favorecer una mayor proximidad entre representantes y representados. Con esto, se busca:

- Una ciudadanía activa que se educa cívicamente durante el mismo proceso participativo.

- Buscar soluciones conjuntas a problemas concernientes a la comunidad.

- Una mayor eficacia en la gestión municipal.

- La posibilidad de dar voz a colectivos tradicionalmente invisibilizados dentro del espacio público.

Dentro de estas iniciativas, el presupuesto participativo es uno de los mecanismos administrativos favoritos y que mejores resultados han dado para alcanzar dichos objetivos. Se trata de un instrumento mediante el cual un gobierno local o regional reserva un porcentaje del presupuesto a los vecinos para su administración y utilización de forma coordinada. No son medidas que traten de sustituir el sistema representativo, sino que en teoría sirven de complemento en aquellos problemas en los que el Ejecutivo muestra menos iniciativa.

El presupuesto participativo aparece por primera vez en 1989, en la localidad brasileña de Porto Alegre, capital del estado Río Grande del Sur. Después del fin de la dictadura militar y del lento proceso de redemocratización del país iniciado por el general Ernesto Geisel en 1974, finalmente, en 1988 se promulgó una Constitución democrática. Las herramientas participativas que les concedía la Constitución (soberanía del pueblo, plebiscitos, referéndums e iniciativas populares tanto a nivel estatal como local, así como la necesidad de utilizar consultas populares para las modificaciones territoriales estatales y municipales) sirvieron como base jurídica para implementar en la ciudad una serie de mecanismos participativos descentralizados, acercando a los ciudadanos a los espacios de toma de decisiones. Rápidamente se convirtió en un método democrático de gestión pública sumamente innovador, siendo reconocido por la ONU en 1994 como una de las 42 mejores prácticas de gestión urbana (Pires y Pineda, 2008). En pocos años, especialmente a partir del año 2000, muchas ciudades del mundo imitarían el experimento brasileño, aunque a menudo adoptando cambios significativos en su metodología y en sus objetivos. Tampoco responden a estrategias nacionales o regionales sistemáticas, sino más bien al impulso de asociaciones o administraciones concretos (Ganuza y Gómez, 2008).

La pluralidad de fórmulas hace difícil establecer una definición única o características específicas sobre lo que es y no es un presupuesto participativo. Aunque podríamos establecer una serie de premisas básicas según lo acordado por distintas redes nacionales y plataformas internacionales en la Declaración de Bogotá (2011): 
Rurali: Revista interdisciplinar de estudios rurales, N. 2, V.1, julio a diciembre de 2021, pp. 3653

a) Autoreglamentado, considerando las particularidades locales y poniendo al servicio del proceso a la Administración Pública.

b) Incluyente, incorporando a los excluidos legales (infancia, inmigrantes) y favoreciendo la participación efectiva de los sectores excluidos y las diversidades.

c) Contando con espacios deliberativos previos al momento decisorio y favoreciendo la construcción de consensos.

d) Democracia directa (un/a participante un voto).

e) En caso de elección de delegados/as estos/as deben tener mandato imperativo de sus asambleas.

f) Vinculante, garantizado el cumplimiento de las decisiones ciudadanas.

g) Con sistemas de seguimiento, control social y rendición de cuentas.

h) Encaminado a la superación de las desigualdades y al disfrute efectivo de los Derechos Humanos.

i) Que cuente con sistemas de información, comunicación y formación que garanticen la autonomía, empoderamiento y apropiación social del proceso.

j) Vinculado a la planificación participada, gestión participativa y el desarrollo del territorio.

k) Con marcos técnicos y administrativos que faciliten estos procesos.

1) Que garantice la participación ciudadana en todas las fases del proceso.

m) Que se realice sobre un monto significativo y progresivo del presupuesto.

n) Práctica continuada.

o) Movilizador de la ciudadanía y transformador de la realidad social.

2. Inicio y desarrollo de los presupuestos participativos en España

Hubo que esperar a 2001 para las primeras experiencias de presupuestos participativos en España, implementándose en tres municipios andaluces de la mano de partidos de ideología de izquierdas: Córdoba, Puente Genil (Córdoba) y Cabezas de San Juan (Sevilla). Posteriormente se irían incorporando a este nuevo modelo municipios como Rubí (Barcelona), Albacete, Almansa (Albacete), Callús (Barcelona), San Sebastián, etc. (Pineda, 2009).

Ernesto Ganuza identifica hasta tres modelos diferentes de presupuestos participativos implantados en España de acuerdo con el tipo de participación que se desenvuelven en ellos. Se calificarían de la siguiente manera: 
Rurali: Revista interdisciplinar de estudios rurales, N. 2, V.1, julio a diciembre de 2021, pp. 3653

MODELO ADMINISTRATIVO (Logroño o Málaga)

- Participa la ciudadanía en general y las asociaciones mediante las estructuras tradicionales de participación.

- Relación top-down: da escasa capacidad de iniciativa a los participantes

- Reglas elaboradas por la Administración y poca autonomía ciudadana.

- No hay deliberación entre la ciudadanía, sólo propone sin participar en otra fase de la toma de decisiones.

- Se tienen en cuenta criterios de justicia distributiva, pero es realizado exclusivamente por la Administración

\section{MODELO REPRESENTATIVO (Albacete)}

- Participan principalmente asociaciones y un Consejo de los presupuestos participativos, donde están representadas aquellas.

-Relación down-top-down: la iniciativa y margen de maniobra que tienen las asociaciones es elevada.

- Reglas del proceso elaboradas por las asociaciones

- La deliberación tiene lugar exclusivamente entre representantes de las asociaciones.

- Se tienen en cuenta criterios de justicia distributiva para priorizar las propuestas, pero su uso es difuso y muy general.

\section{MODELO PARTICIPATIVO (Sevilla)}

- Participa la ciudadanía en general mediante asambleas abiertas, pero también las asociaciones en el proceso de toma de decisiones, dentro del órgano creado a tal fin: el Consejo de los presupuestos participativos.

- Relación top-down-top: la iniciativa parte del gobierno, pero el proceso es concebido junto a los participantes, que pueden sugerir modificaciones y modificar parcialmente el funcionamiento de los presupuestos participativos.

- Las reglas son elaboradas por los participantes y la administración.

- La deliberación se da entre la ciudadanía cuando se hacen propuestas.

- Se discute públicamente qué criterios de justicia distributiva se aplicarán para hacer la priorización final de las propuestas. Su aplicación es pública y hay que justificarla ante terceros. 
No obstante, estas iniciativas no parten jurídicamente de la nada. Desde los inicios de nuestra democracia la Constitución ha supuesto el punto de partida para el desarrollo de un marco normativo de la participación ciudadana en el ámbito municipal, aunque sea a un nivel genérico. El artículo 9.2 establece que "corresponde a los poderes públicos (...) remover los obstáculos que impidan o dificulten su plenitud y facilitar la participación de todos los ciudadanos en la vida política, económica, cultural y social". A continuación, establece en el art. 23 que "los ciudadanos tienen el derecho a participar en los asuntos públicos, directamente o por medio de representantes, libremente elegidos en elecciones periódicas por sufragio universal". Mientras que el art. 140 garantiza la autonomía municipal, gozando de personalidad jurídica plena, lo que les otorga capacidad de gasto según los límites establecidos por la ley. Como se ve, la Constitución no establece ni el modo ni el ámbito territorial por el que se articula dicha participación, sin embargo, esta indefinición permite que distintas administraciones locales puedan gestionar ciertas propuestas participativas.

Posteriormente, en la Ley 7/1985 Reguladora de las Bases de Régimen Local, en sus artículos 1, 69, 70, 71 y 72 se contemplan medidas básicas por el que se articulan ciertos aspectos de la participación ciudadana. En ellos se garantiza la potestad tributaria y financiera de los municipios, e insta a las corporaciones locales a facilitar la participación de todos los ciudadanos en la vida local. Por ejemplo, el art. 70.1 bis. reconoce que "los ayuntamientos deberán establecer y regular en normas de carácter orgánico procedimientos y órganos adecuados para la efectiva participación de los vecinos en los asuntos de la vida pública local, tanto en el ámbito del municipio en su conjunto como en el de los distritos, en el supuesto de que existan en el municipio dichas divisiones territoriales". Pese al avance que supuso como base normativa para la gestión local, la ley no reconoce que dicha participación tenga que ser necesariamente directa, aunque serviría para poner en marcha los primeros experimentos de participación presupuestaria anteriormente mencionados. Dieciocho años después, la Ley 57/2003 de Medidas para la Modernización del Gobierno Local, en sus artículos 24 y 70, instaría a los ayuntamientos a establecer procedimientos y órganos adecuados para la efectiva participación de los vecinos en los asuntos de la vida pública local.

Aunque no se tiene un registro claro del número de experiencias realizadas durante aquellos primeros años, algunos estudios estiman que en 2004 se implementaron presupuestos participativos en unos 12 municipios, llegando a más de 70 en 2010 (Pineda, 2009). No obstante, los presupuestos participativos han padecido muchos problemas para mantenerse activos a lo largo del tiempo. La continuidad o desaparición de esta práctica queda marcada por varias razones (metodología escogida, nivel de participación, la capacidad de responder a las demandas ciudadanas, etc.), pero López y Pineda (2013) resaltan las dos más influyentes: primero, a la correlación de fuerzas existentes tras las elecciones. En última instancia, estas prácticas participativas no obedecen a programas coordinados de los partidos políticos, sino a un compromiso concreto del gobierno municipal de turno. Cuando dicho compromiso desaparece, lo hace también el presupuesto participativo. La segunda razón se debe a la crisis económica surgida en 
2008, cuando el gobierno central, al tratar de reducir el déficit, redujo sustancialmente las inversiones, lo que repercutió rápidamente en los gobiernos locales, especialmente tras las elecciones de 2011 y la llegada del Partido Popular al Gobierno. En este periodo se eliminaron experiencias pioneras como la de Sevilla, Albacete o Getafe.

Esta situación dio un vuelco unos años después. La desafección ciudadana provocada por la depresión económica y la falta de confianza en los políticos por los numerosos casos de corrupción, dieron como resultado la aparición de nuevos movimientos y partidos, muchos vinculados a las reivindicaciones del $15 \mathrm{M}$, que irrumpieron con más o menos fuerza en el panorama político nacional y municipal. El primer caso de este tipo fue el éxito de Podemos en las elecciones europeas de 2014. Pero fue a partir de 2015 cuando se conoce un crecimiento cuantitativo en enfoques y metodologías de la participación ciudadana, según Monterde (2019):

Múltiples proyectos municipalistas irrumpieron con fuerza y de manera inesperada en las principales ciudades de España, llegando al gobierno en algunas de ellas y consiguiendo representación en muchas otras. Bajo nombres diferentes, siglas diferentes, formas organizativas diferentes y con un sentir común, esos proyectos entraban en escena en varios gobiernos municipales ${ }^{1}$ (p. 25).

Esto supuso una revitalización de los presupuestos participativos, multiplicándose en todo el territorio nacional, incorporándose en grandes ciudades como Valencia o A Coruña (Barandela, 2017).

También vemos en estos años una plasmación en las disposiciones normativas de estas nuevas sensibilidades municipalistas, como en el caso de muchas leyes autonómicas, donde los presupuestos participativos aparecen, ya sea como manifestaciones de estas o porque la misma ley explicita su uso como un derecho de los ciudadanos. Así, se actualizaría el marco normativo con leyes tales como: la Ley 4/2013, de 21 de mayo, Gobierno abierto de Extremadura; Ley 12/2014, 16 de diciembre, de Transparencia y Participación Ciudadana de la Comunidad Autónoma de la Región de Murcia; Ley 3/2015, 4 de marzo, de Trasparencia y Participación ciudadana de Castilla y León; Ley 8/2015, de 25 de marzo, de Transparencia de la Actividad de la Actividad Pública y Participación Ciudadana de Aragón; Ley 2/2015, 2 de abril, de Transparencia, Buen Gobierno y Participación Ciudadana de la C. Valenciana; Ley 7/2015, 1 de abril, de los Municipios de Canarias; Ley 2/2016, 7 de abril, de Instituciones Locales de Euskadi; Ley 7/2017, 27 de diciembre, de Participación Ciudadana de Andalucía; Ley Foral 12/2019, 22 de marzo, de Participación Democrática en Navarra; Ley 8/2019, 13 de diciembre, de Participación de Castilla-La Mancha.

\footnotetext{
${ }^{1}$ Aparecen multitud de candidaturas en las elecciones municipales en cuyos nombres aparecen palabras como "En Común”, “Ahora”, "Participa", "Cambiemos", "Imagina”, "Somos”, etc.
} 
Rurali: Revista interdisciplinar de estudios rurales, N. 2, V.1, julio a diciembre de 2021, pp. 3653

\section{Presupuestos Participativos en España durante el "año Covid"}

Fue el 14 de marzo de 2020 cuando el Gobierno declaró, mediante el Real Decreto-ley 463/2020, el estado de alarma en todo el territorio español. Se confinó a casi toda la población en sus hogares con el objetivo de frenar la expansión del coronavirus, provocando una alarmante situación tanto a nivel sanitario, como social, político y económico. El Congreso de los Diputados prorrogó la situación hasta seis veces, específicamente, el 25 de marzo, el 9 y 22 de abril, el 6 y 20 de mayo y el 3 de junio. Después de tres meses, el 21 de junio, se levantó el estado de alarma, aunque ello no impidió una segunda ola de contagios. El 25 de octubre, el Gobierno decretó un nuevo estado de alarma que acabarían prorrogando hasta el 9 de mayo de $2021^{2}$. Esta vez no se confinaría a la población, aunque sí se establecieron limitaciones a la movilidad y a la reunión.

Se trata de una situación de excepcionalidad sin precedentes en nuestra democracia, afectando en todos los niveles del Estado y los presupuestos participativos no son la excepción. Del mismo modo que en crisis anteriores, la Covid-19 ha supuesto un desafío para el desarrollo de estas iniciativas participativas, paralizando algunas, mientras que otros se han visto obligados a adaptarse para dar cabida a los reclamos ciudadanos. La pandemia ha afectado a municipios grandes, medianos y pequeños, sin excepción. Y como veremos a continuación, tanto la administración, como las asociaciones y los vecinos han jugado un papel determinante en la continuidad o parálisis de los presupuestos este año. No obstante, hay que tener en cuenta ciertos aspectos, como las circunstancias particulares de cada municipio y en el punto en el que se encontraba el estado de alarma en el momento de iniciarse el proceso presupuestario.

Teniendo estos elementos presentes, se expondrán a continuación una serie de municipios seleccionados por su valor cualitativo, algunos siendo representativos de una serie de tendencias que se repiten con algunas variantes por el territorio español. Empezaremos por la más obvia.

\subsection{Parálisis de los presupuestos participativos}

La pandemia ha obligado a aplazar o destinar ese porcentaje de las cuentas municipales a otros proyectos. Tal es el caso de Melilla (87.076 habitantes en 2020 según el Instituto Nacional de Estadística), donde en abril, uno de los meses más duros, el ayuntamiento decidió aplazar a 2021 los proyectos votados en los presupuestos participativos. Un proceso iniciado el 1 de agosto de 2019 y que contaba con una partida de 4.600 .000 euros (Ciudad Autónoma de Melilla, 2020). En palabras del consejero de distritos, Mohamed Ahmed, en una rueda de prensa el 22 de abril:

Nosotros ahora mismo estamos en la modificación de presupuestos, a raíz de lo que estamos padeciendo ahora mismo, casos de familias necesitadas, empresas

\footnotetext{
${ }^{2}$ En el momento de escribir este texto, enero de 2021, todavía no hemos alcanzado dicha fecha.
} 
que pasan dificultades... y desde la consejería que yo llevo hemos decidido seguir manteniendo el compromiso con los presupuestos participativos, pero desplazarlo a 2021 para así disponer de esa parte del presupuesto para algo que es más requerido como es ayudar a familias y empresas. (FaroTV Melilla, 2020, 0:10).

En este caso el ayuntamiento decidió disponer del dinero para paliar los efectos causados por la pandemia, siendo las familias y las empresas su prioridad. Una situación muy parecida que la padecida en Elche (Alicante, 234.765 hab.). Desde 2015 el gobierno municipal había dotado anualmente con un millón de euros los presupuestos participativos de la ciudad, sin embargo, la crisis de la pandemia obligó al gobierno bipartito de PSPV-PSOE y Compromís a acentuar el carácter social de los presupuestos. Lo que supuso retrasar la convocatoria de los presupuestos participativos hasta 2022, con el consentimiento de la Federación de Asociaciones de Vecinos de Elche (Alberola, 2020).

La experiencia de Conil de la Frontera (Cádiz, 22.775 hab.) fue algo distinta. Al igual que en los anteriores casos, el ayuntamiento tomó en octubre la decisión de trasladar los presupuestos participativos a 2021. Esta medida fue presentada por delegada de participación ciudadana, María del Carmen Mendoza, tras una reunión con la comisión de seguimiento de los presupuestos participativos. Pero esta vez la razón fue la incapacidad de organizar asambleas de ciudad y foros donde los vecinos pudieran deliberar sobre las cuestiones municipales, aunque continuarían realizando los proyectos aprobados de 2019 (Tuya La Janda Televisión, 16 de octubre de 2020). A diferencia de Melilla o Elche, el aplazamiento no se debió a la necesidad de disponer de todo el presupuesto para combatir la pandemia, sino en su falta de adaptación a la nueva situación.

Soto del Real (Madrid, 8.981 hab.) trató de buscar un punto medio. En junio se decidió suspender su sexta edición de presupuestos participativos, cuya partida iba a ser de 180.000 euros y que se iban a llevar a cabo mediante una consulta, en el que los vecinos escogerían entre una serie de propuestas. De nuevo, el objetivo era ayudar a aquellos afectados por el coronavirus. No obstante, se acordó que se mantendría la asamblea institucional para el 28 de junio. Desde el ayuntamiento, consideraron que, pese a no haber presupuestos participativos, era importante dar la oportunidad a los vecinos de presentar sus inquietudes y sugerencias a los representantes políticos. Siempre respetando las medidas de precaución sanitarias ("Soto suspende su presupuesto participativo para ampliar ayudas de coronavirus", 2020). Para este municipio el proceso deliberativo poseía un valor simbólico que había que preservar pese a la situación.

No todas las iniciativas de aplazar los presupuestos participativos provinieron del ayuntamiento. Tal es el ejemplo de Benidorm (Alicante, 70.450 hab.), donde en abril fue el propio Consejo Vecinal quien elaboró un escrito pidiendo al ayuntamiento que dispusiera de los 500.000 euros reservados para los presupuestos participativos en ayudar a las familias más afectadas, a los autónomos y a las empresas. El alcalde de la ciudad, Antonio Pérez Pérez, alabó la propuesta del Consejo "que le honra y que demuestra su 
sensibilidad y compromiso con la ciudadanía, al poner a disposición del Ayuntamiento un importe destinado inicialmente a ejecutar proyectos de mejora planteados por los propios vecinos" (Morarodero, 2020).

Por último, hay otra situación que considero que se debe señalar. Como se ha apuntado en el apartado anterior, la participación presupuestaria suele ser una actividad marginal dentro de la política municipal. Ya sea por una plataforma web descuidada o porque ciertos comunicados sobre estas cuestiones no se suban a internet, muchas experiencias se han suspendido abruptamente y sin razón oficial. Este es el caso de Figaró-Montmany (Barcelona, 1.142 hab.), un pequeño pueblo conocido desde hace años por su manera de gestionar los recursos municipales de manera asamblearia (Mumbrú, 2013). Si se busca en la página web del ayuntamiento y en la plataforma de participación ciudadana habilitada (Decidim Figaró), se observa una parálisis completa en el proceso participativo de 2019. De hecho, según los plazos establecidos en Decidim Figaró, todavía no se ha superado la tercera y última fase "Jornada participativa: taller de futur obert", cuya consecución se preveía para finales de marzo de 2020, justo en las semanas iniciales del confinamiento. Desde el tablón de noticias en la web del ayuntamiento se puede intuir que los problemas ocasionados por la Covid-19 han imposibilitado continuar con el desarrollo de los presupuestos participativos, si bien es cierto que no han emitido por internet un comunicado oficial al respecto. Y como este, otros municipios.

\subsection{Presupuestos participativos activos}

Pese al desafío que ha supuesto para los municipios españoles la inesperada llegada de la pandemia, numerosos presupuestos participativos han logrado seguir adelante en 2020. El método más común utilizado para continuar con el proceso ha sido habilitar un correo electrónico oficial o una página web en donde los vecinos pudiesen presentar o apoyar proyectos específicos. Algunos transcurrieron con normalidad, como han sido los casos de Salamanca (329.245 hab.), en donde se sustituyeron los buzones presenciales distribuidos por la ciudad por el buzón corporativo presupuestosparticipativos@aytosalamanca.es, o mediante el registro municipal, lo que permitió a los empadronados participar; Las Palmas de Gran Canarias (381. 223 hab.) prepararon una serie de tutoriales donde explicaron cómo registrarse y votar entre las distintas iniciativas a elegir en la web www.decidelaspalmasgc.es; en Vila-real (Castellón, 51.293 hab.) el vicepresidente del Consejo de Participación Ciudadana, Joaquín Bartoll, declaró que la Covid había condicionado el cumplimiento de los presupuestos participativos, ejecutando el 67\% del total y el resto desplazados para 2021. Aun así, se habilitó el correo participacio@vila-real.es para que los ciudadanos pudieran enviar sus sugerencias para posteriormente ser evaluadas por el Consejo de Participación Ciudadana (Ayuntament de Vila-real, 2020).

En algunos municipios, en cambio, aunque se seguirían manteniendo los presupuestos participativos, se darían prioridad a aquellas propuestas con mayor valor social y económico. Así encontramos declaraciones como las del concejal de Participación 
Rurali: Revista interdisciplinar de estudios rurales, N. 2, V.1, julio a diciembre de 2021, pp. 3653

Ciudadana de Logroño (152.727 hab.), Kilian Cruz-Dunne, quien instó a la ciudadanía a tener en cuenta la crisis sanitaria a la hora de proponer ideas:

Dadas las circunstancias especiales que estamos atravesando de crisis sanitaria y económica, pedimos que las ideas y propuestas tengan en cuenta el momento que estamos viviendo y contribuyan al ahorro del presupuesto municipal [...] Se priorizarán aquellas propuestas que conlleven un valor asumible para el Ayuntamiento y que tiendan a la generación de empleo y al ahorro en inversión y en mantenimiento (Ayuntamiento de Logroño, 2020).

El ayuntamiento de Bellreguard (Valencia, 4.618 hab.) utilizó una fórmula muy parecida cuando el Consejo de Participación Ciudadana acordó por unanimidad, y por primera vez en su historia, adaptar la metodología de los Presupuestos Participativos. En primer lugar, acortaron los plazos de presentaciones de ideas hasta el 24 de mayo, y sólo a través de un whatsapp municipal o por unos buzones colocados en el ayuntamiento (Bodí, 2020). Después, en un comunicado desde el consistorio se explicó que

La crisis sanitaria provocada por la pandemia de la Covid-19 hizo que la Concejalía de Participación Ciudadana reorientara los Presupuestos Participativos dedicándolos exclusivamente a proyectos e iniciativas que tuvieran un trasfondo social y, por lo tanto, contribuyeron a paliar el impacto de la epidemia de coronavirus sobre la población ("Las propuestas de los Presupuestos Participativos de Bellreguard palían los efectos de la pandemia”, 2021).

En contraposición a los anteriormente citados, en municipios como el de Formentera (Islas Baleares, 11.904 hab.) no hizo falta que el ayuntamiento condicionase el resultado de los presupuestos participativos. Debido a la notable caída del turismo, principal fuente de ingresos de la zona, todas las asociaciones del Consell d'Entitats aprobaron por unanimidad en abril que los 325.000 euros de la partida de ese año serían destinados a combatir los efectos económicos y sociales de la crisis (Convalia, 2020).

En otros casos, los ayuntamientos se vieron obligados a innovar si querían adaptarse a la nueva situación. Esta fue la experiencia de Cartes (Cantabria, 5.731 hab.), que por primera vez en su historia apostaron por el uso de la tecnología en el proceso de presupuestos participativos para superar las medidas restrictivas impuestas por la pandemia. En octubre, dado que les era imposible sus tradicionales concejos abiertos, el ayuntamiento trabajó para desarrollar una aplicación informática para darle la oportunidad a los vecinos de transmitir sus propuestas. En palabras de Sheila Ruiz García, concejal de Barrios y Participación Ciudadana:

Los concejos abiertos siguen siendo una herramienta que nos permite conocer de primera mano las necesidades de los 11 pueblos cartiegos, escuchar sus necesidades y planificar entre corporación y vecinos los presupuestos municipales. Desgraciadamente, ese formato, utilizado en años anteriores, no puede aplicarse a esta delicada situación sanitaria que estamos atravesando [...] este año, gracias a la tecnología y mirando por la salud de nuestros vecinos y del 
medio ambiente, respondemos apostando de nuevo por las personas, como hemos venido haciendo hasta ahora, escuchando sus necesidades para resolver sus problemas cotidianos. (Cavia, 2020).

En ciertas experiencias, todo parecía indicar que los presupuestos participativos se aplazarían o que se usaría ese porcentaje presupuestario para otras cuestiones presupuestarias. Sólo gracias al compromiso, de la administración unas veces, y de la ciudadanía en otras, se logró sacar adelante el proceso. Un ejemplo del primer caso es Galdakao (Bizkaia, 29.427 hab.), donde el gobierno local conformado por EH Bildu, Podemos y las plataformas independientes Auzoak y Usansolo Herria, mantuvieron en diciembre, en contra de lo esperado, la dotación de un millón de euros a los presupuestos participativos pese a caer un $11 \%$ las cuentas municipales para 2021. Los partidos de la oposición se situaron en contra de esta decisión, puesto que mantener el millón de los presupuestos participativos con aquel descenso presupuestario significaría dejar apenas unos 200.000 euros para otros proyectos (Raposo, 2020). Rivas-Vaciamadrid (Madrid, 90.973 hab.) es un claro ejemplo del segundo caso. Con una partida presupuestaria de 350.000 euros, ya desde abril distintos grupos en el municipio propusieron suspender los presupuestos participativos y usar el dinero en paliar el daño económico de la pandemia, al igual que se estaban haciendo en otras ciudades ("Ciudadanos Rivas propone suspender los presupuestos participativos $2020 \mathrm{y}$ destinar el dinero a ayudas directas para empleados y autónomos afectados por el coronavirus", 2020). En junio se pospuso el periodo para que los vecinos votaran vía online las propuestas, y es que la emergencia sanitaria y socioeconómica obligaba al ayuntamiento a dar respuesta a las necesidades inmediatas de los vecinos ("Rivas pospone la votación de sus presupuestos participativos por la COVID19”, 2020). La situación no era muy esperanzadora, sin embargo, el concejal de Participación, Alberto Cabeza, calificó de "excepcional" la participación ciudadana en los últimos meses:

El nivel de participación ha sobrepasado en mucho las mejores de nuestras expectativas. Sólo unos datos: se han registrado durante el periodo de votaciones 897 usuarios nuevos, que no habían participado otros años. Pero hay más, este año 2020 los usuarios que se han registrado en los diversos procesos participativos han sido 7.942, mientras que a finales de 2019 eran 3.600, lo que supone un aumento espectacular en términos absolutos de participación en los diversos procesos de la concejalía. Y ha habido 6.576 visualizaciones del proceso participativo en la web de participación ciudadana. ("El Presupuesto Participativo de Rivas se sobrepone al coronavirus", 2020).

El papel activo y comprometido de los vecinos de Rivas fue lo que finalmente logró salvar el proceso, concluyendo su tercera edición aprobando 14 propuestas. Se consolida así los presupuestos participativos en este municipio como una herramienta para el futuro. 
Rurali: Revista interdisciplinar de estudios rurales, N. 2, V.1, julio a diciembre de 2021, pp. 3653

\section{Conclusión}

Como hemos podido comprobar los presupuestos participativos tienen muchas dificultades para expandirse y consolidarse en el tiempo, aunque en los últimos años su número se ha incrementado considerablemente. La crisis sanitaria ha puesto a prueba estos procesos en muchos municipios españoles, que han destacado por su pluralidad de fórmulas tanto para llevarlas a cabo como no durante el 2020. Al no existir una metodología única o un programa sistemático común de presupuestos participativos, estas siempre deben quedar enmarcadas como experiencias que se ajustan según las realidades políticas, sociales y económicas en las que se desenvuelven. E independientemente del tamaño o los recursos del municipio que las desarrolle o de las siglas políticas de turno. Su continuidad ha tenido mucho que ver con el compromiso tanto del equipo de gobierno como de los vecinos, además del diseño institucional y tecnológico para responder a los problemas con eficacia, ganando en el proceso calidad y esperanzas de durabilidad. El tiempo dirá si la pandemia fortalecerá los mecanismos para una mejor comunidad democrática, o si será la causa de su retroceso como supuso la crisis económica de 2008.

\section{Referencias}

\section{Libros y artículos}

- Albet i Mas, Abel (2019). El mapa municipal en España: estructura, evolución y problemáticas. Geopolítica(s). Revista de estudios sobre espacio y poder, 10 (1), 11-40.

- Burgueño, Jesús y Guerrero Lladós, Montse (2014). El mapa municipal de España. Una caracterización geográfica. Boletín de la Asociación de Geógrafos Españoles, 64, 11-36.

- Fernández Rodríguez, Carlos Jesús y Pineda Nebot, Carmen (2010). La sostenibilidad de los presupuestos participativos: el caso del «presupuesto ciudadano» de Logroño. Revista de Estudios Políticos (nueva época), 148, 159-189.

- Ganuza Fernández, Ernesto y Gómez Fortes, Braulio (2008). Control político y participación en democracia: los presupuestos participativos. Estudios de progreso, 38, $1-52$.

- Grompone, Romeo (2006). El heterogéneo universo de los presupuestos participativos provinciales y distritales. Instituto de Estudios Peruanos.

- López Ronda, Sergio y Pineda Nebot, Carmen (2013). Experiencias de presupuestos participativos en el País Valenciano: análisis de variables que intervienen en su paralización. OBETS. Revista de Ciencias Sociales, 8 (2), 259-286.

- Macpherson, C. B (2003). La democracia liberal y su época. Alianza. 
Rurali: Revista interdisciplinar de estudios rurales, N. 2, V.1, julio a diciembre de 2021, pp. 3653

- Monterde, Arnau (2019). De la emergencia municipalista a la ciudad democrática. En Roth, Laura; Monterde, Arnau y Calleja López, Antonio (eds.). Ciudades democráticas. Icaria (pp. 25-52).

- Pérez Zafrilla, Pedro Jesús (2014). Génesis y estructura de la democracia deliberativa. En Aznar, Hugo y Pérez Llavador, Jordi (eds.). De la democracia de masas a la democracia deliberativa. Ariel (pp. 139-160).

- Pires, Valdemir y Pineda Nebot, Carmen (2008). Presupuesto Participativo: una tipología para superar los límites de las definiciones demasiado amplias o restrictivas. Revista de Estudios de la Administración Local y Autonómica, 308, 207-246.

- Pineda Nebot, Carmen (2009). Los Presupuestos Participativos en España: un nuevo balance. REALA. Revista de Estudios de la Administración Local y Autonómica, 311, 279301.

- Ramírez Nárdiz, Alfredo (2009). Los presupuestos participativos como instrumento de democracia participativa (La experiencia de San Juan de Alicante). Cuadernos Constitucionales de la Cátedra Fadrique Furió Ceriol, 66, 127-144.

- Schumpeter, J.A (1984). Capitalismo, socialismo y democracia. Folio.

\section{Prensa}

- Alberola García, David (27 de noviembre de 2020). La covid-19 elimina en Elche el proceso de presupuestos participativos en 2021. Onda Cero. https://www.ondacero.es/emisoras/comunidad-valenciana/elche/noticias/covid19elimina-elche-proceso-presupuestos-participativos2021_202011275fc0feaadd004e0001df10de.html

- Alonso, Iñaki (29 de mayo de 2017). El regreso de los presupuestos participativos. elCorreo. https://elcorreoweb.es/sevilla/el-regreso-de-los-presupuestos-participativosIG3008912.

- Barandela, Marta (21 de mayo de 2017). Se multiplican los presupuestos participativos en España: "La gente demanda expresarse en primera persona". elDiario.es. https://www.eldiario.es/politica/presupuestos-participativos_1_3413259.html.

- Bodí, Enrique (18 de mayo de 2020). Los presupuestos participativos de Bellreguard irán destinados a reducir el impacto del coronavirus. Cadena Ser. https://cadenaser.com/emisora/2020/05/18/radio_gandia/1589798954_627296.html.

- Cavia, Nacho (22 de octubre de 2020). Cartes abre una aplicación para la participación ciudadana en los presupuestos. El Diario Montañés. https://www.eldiariomontanes.es/region/besaya/cartes-abre-aplicacion20201022110859-nt.html 
Rurali: Revista interdisciplinar de estudios rurales, N. 2, V.1, julio a diciembre de 2021, pp. 3653

- Convalia, Carmelo (21 de abril de 2020). El presupuesto participativo de Formentera irá a asuntos sociales. Diario de Ibiza. https://www.diariodeibiza.es/formenterahoy/2020/04/22/presupuesto-participativo-formentera-ira-asuntos/1138159.html.

- Ciudadanos Rivas propone suspender los presupuestos participativos 2020 y destinar el dinero a ayudas directas para empleados y autónomos afectados por el coronavirus (2 de abril de 2020). Diario de Rivas. https://www.diarioderivas.es/ayudas-trabajadoresautonomos-coronavirus/.

- El Presupuesto Participativo de Rivas se sobrepone al coronavirus (29 de noviembre de 2020). Rivas Actual. https://www.rivasactual.com/el-presupuesto-participativo-de-rivasse-sobrepone-al-coronavirus/.

- Las propuestas de los Presupuestos Participativos de Bellreguard palían los efectos de la pandemia (4 de enero de 2021). Gente de la Safor. http://gentedelasafor.es/art/6048/laspropuestas-de-los-presupuestos-participativos-de-bellreguard-palian-los-efectos-de-lapandemia.

- Morarodero, Manuel (24 de abril de 2020). El Consejo Vecinal pone a disposición del ayuntamiento de Benidorm los 500.000 euros del presupuesto participativo para ayudas frente al Covid-19. Calvari. El periódic del cor de Benidorm. https://calvarielperiodicdelcordebenidorm.com/2020/04/24/el-consejo-vecinal-pone-adisposicion-del-ayuntamiento-de-benidorm-los-500-000-euros-del-presupuestoparticipativo-para-ayudas-frente-al-covid19/.

- Munbrú, Jordi (26 de noviembre de 2013). Figaró, un pueblo asambleario en el que hasta los niños tienen acceso a los presupuestos. Eldiario.es. https://www.eldiario.es/catalunya/politica/buscan-conocer-ejemplo-democraciaparticipativa_1_5145029.html

- Raposo, Cristina (10 de diciembre de 2020). La pandemia obliga al Ayuntamiento de Galdakao a reducir sus Cuentas un $11 \%$. El Correo. https://www.elcorreo.com/bizkaia/nervion/pandemia-obliga-ayuntamiento20201210215239-nt.html.

- Rivas pospone la votación de sus presupuestos participativos por la COVID-19 (14 de junio de 2020). La Vanguardia. https://www.lavanguardia.com/politica/20200614/481771266569/rivas-pospone-lavotacion-de-sus-presupuestos-participativos-por-la-covid-19.html.

- Soto suspende su presupuesto participativo para ampliar ayudas de coronavirus (22 de junio de 2020). La https://www.lavanguardia.com/vida/20200622/481897512331/soto-suspende-supresupuesto-participativo-para-ampliar-ayudas-de-coronavirus.html. 
Rurali: Revista interdisciplinar de estudios rurales, N. 2, V.1, julio a diciembre de 2021, pp. 3653

\section{Legislación}

- Constitución Española de 1978

- Ley 7/1985, de 2 de abril, Reguladora de las Bases del Régimen Local, BOE núm. 80 (1985).

- Ley 57/2003, de 16 de diciembre, de medidas para la modernización del gobierno local, BOE núm. 301 (2003).

- Ley 45/2007, de 13 de diciembre, para el desarrollo sostenible del medio rural, BOE núm. 299 (2007).

- Ley 4/2013, de 21 de mayo, de Gobierno Abierto de Extremadura, BOE núm. 136 (2013).

- Ley 12/2014, de 16 de diciembre, de Transparencia y Participación Ciudadana de la Comunidad Autónoma de la Región de Murcia, BOE núm. 290 (2014).

- Ley 3/2015, 4 de marzo, de Trasparencia y Participación ciudadana de Castilla y León, BOE núm. 74 (2015).

- Ley 8/2015, de 25 de marzo, de Transparencia de la Actividad de la Actividad Pública y Participación Ciudadana de Aragón, BOE núm. 115 (2015).

- Ley 2/2015, 2 de abril, de Transparencia, Buen Gobierno y Participación Ciudadana de la C. Valenciana, BOE núm. 100 (2015).

- Ley 7/2015, 1 de abril, de los Municipios de Canarias, BOE núm. 101 (2015).

- Ley 2/2016, 7 de abril, de Instituciones Locales de Euskadi, BOE núm. 105 (2016).

- Ley 7/2017, 27 de diciembre, de Participación Ciudadana de Andalucía, BOE núm. 33 (2017).

- Ley Foral 12/2019, 22 de marzo, de Participación Democrática en Navarra, BOE núm. 91 (2019).

- Ley 8/2019, 13 de diciembre, de Participación de Castilla-La Mancha, BOE núm. 31 (2019).

- Real Decreto 463/2020, de 14 de marzo, por el que se declara el estado de alarma para la gestión de la situación de crisis sanitaria ocasionada por el COVID-19. BOE núm. 67 (2020).

\section{Recursos audiovisuales y PowerPoint}

- FaroTV Melilla (22 de abril de 2020). Los proyectos de los presupuestos participativos se aplazan a 2021 [Video]. Youtube. 
Rurali: Revista interdisciplinar de estudios rurales, N. 2, V.1, julio a diciembre de 2021, pp. 3653

https://www.youtube.com/watch?v=7i2QqSi3Y44\&feature=emb_title\&ab_channel=Far oTVMelilla

- Ganuza Fernández, Ernesto. Los presupuestos participativos en España [diapositivas de PowerPoint].http://www.presupuestosparticipativos.info/ES/seccion/descarga/repo/repo file $55 \mathrm{e} 86254 \mathrm{e} 059 \mathrm{e}$

- Tuya La Janda Televisión (16 de octubre de 2020). El Covid-19 paraliza los presupuestos participativos en Conil [Video]. Youtube.

https://www.youtube.com/watch?v=zUCYoXudlqA\&ab_channel=TuyaLaJandaTelevisi \%C3\%B3n

\section{Documentos}

- Declaración de Bogotá (15 de junio de 2011). https://www.ucm.es/data/cont/docs/32016-03-02-declaracion\%20de\%20bogota.pdf

\section{Webs}

- Ayuntamiento de Logroño (13 de agosto de 2020). El Presupuesto Participativo refuerza su difusión y amplía el plazo de recepción de propuestas de la ciudadanía hasta $\begin{array}{lllll}\text { el } & 26 & \text { de } & \text { agosto. }\end{array}$ 0wa.es/wps/portal/web/inicio/ayuntamiento/gabinetePrensa/notasPrensa/!ut/p/c4/04_SB 8K8xLLM9MSSzPy8xBz9CP0os3hTF98Af293QwMDDwsLA09H42AjNx9_A2djM_2 CbEdFANMUOTI!/?WCM_GLOBAL_CONTEXT=/web_es/logrono/secciones/ayunta miento/gabinetePrensa/notasPrensa/13082020104641

- Ayuntament de Vila-Real (22 de octubre de 2020). Los Presupuestos Participativos se reinventan para canalizar propuestas vecinales y retomar proyectos parados por la covid-19

https://www.vilareal.es/portal/p_20_contenedor $1 . j s p ?$ seccion $=$ S_fnot_d4_v1.jsp\&contenido=57365\&tipo $=8 \&$ nivel $=1400 \&$ layout $=$ p_20_contenedor $1 . j$ sp $\&$ codResi=1\&language $=e s$

- Ciudad Autónoma de Melilla (17 de enero de 2020). Presupuestos Participativos Melilla 2020. https://www.melilla.es/melillaportal/index.jsp?codResi=1

- Decidim Figaró-Montmany (s.f.). Pressupostos participatius 2019. Decidim Figaró 2019. https://decidim-figaro.diba.cat/processes/pressupostos2019/steps?locale=es

- Instituto Nacional de Estadística. https://www.ine.es/ 